\begin{abstract}
Iranica
Abstracta Iranica Revue bibliographique pour le domaine irano-aryen

Volume 28 | 2007

Comptes rendus des publications de 2005

\section{Iranian Studies. Journal of The International Society for Iranian Studies. Vol. 38, n 3, September 2005.}

Rédaction

\title{
OpenEdition
}

12 Journals

\section{Édition électronique}

URL : http://journals.openedition.org/abstractairanica/7592

DOI : 10.4000/abstractairanica.7592

ISSN : 1961-960X

Éditeur :

CNRS (UMR 7528 Mondes iraniens et indiens), Éditions de l'IFRI

\section{Édition imprimée}

Date de publication : 15 mai 2007

ISSN : 0240-8910

\section{Référence électronique}

Rédaction, «Iranian Studies. Journal of The International Society for Iranian Studies. Vol. 38, $n^{\circ} 3$, September 2005. 》, Abstracta Iranica [En ligne], Volume 28 | 2007, document 516, mis en ligne le 18 septembre 2007, consulté le 25 septembre 2020. URL : http://journals.openedition.org/ abstractairanica/7592 ; DOI : https://doi.org/10.4000/abstractairanica.7592

Ce document a été généré automatiquement le 25 septembre 2020.

Tous droits réservés 


\title{
Iranian Studies. Journal of The International Society for Iranian Studies. Vol. 38, $\mathrm{n}^{\circ}$ 3, September 2005.
}

\author{
Rédaction
}

1 C'est la première fois que cette revue, après 38 ans d'existence, consacre un numéro entier à la musique. Ce numéro, sous la direction de Wendy DeBano et Âmeneh Youssefzâdeh, comporte cinq articles, une introduction et un élément bibliographique assez exhaustif qui liste séparément les livres en persan, les livres en anglais, en français et en allemand, les thèses et les articles écrits sur toutes les catégories de la musique iranienne. La partie consacrée aux comptes-rendus de livres n'est pas inclue dans la thématique de ce numéro, car, selon les éditeurs, les livres récents sur la musique iranienne ont déjà fait l'objet de comptes-rendus dans d'autres revues.

Dans l'Introduction («Music and Society in Iran, A look at the Past and Present Century ", pp. 367-372), Wendy DeBano présente l'objectif du numéro: être à la fois d'intérêt scientifique et accessible aux non-musiciens tout en se focalisant sur le développement récent de la vie musicale en Iran.

3 Jean During, dans le premier article, «Third Millenium Tehran: Music! », pp. 373-398, donne un aperçu général des tendances musicales actuelles en Iran, perçues par un musicien traditionnel imaginaire qui rentre dans le pays après presque 35 ans. Un vaste éventail de faits est observé par ce musicien, nommé « M. » dans l'article (c'est sans doute l'A. lui-même), provoquant en lui des sentiments et des jugements divers. En se basant sur ces observations, l'A. traite des sujets comme la tradition et l'innovation dans la musique iranienne, la légalisation de la popular music dans le pays, l'état actuel des recherches scientifiques sur la musique en Iran, etc.

4 L'évolution de la musique traditionnelle des fêtes urbaines du XIX $\mathrm{s}$. au début du XX $\mathrm{s}$. aboutissant à l'apparition de la musique et du spectacle rūhow dị est le sujet du deuxième article : Sasan Fatemi, « Music, Festivity, and Gender in Iran from the Qajar to 
the Early Pahlavi Period», pp.399-416. Cette évolution est étudiée en prenant en compte la dichotomie féminin/masculin. Au début du XXe s., selon l'A., les femmes musiciennes cèdent aux hommes leur place dominante dans la sphère de la musique des fêtes urbaines, tandis que les musiciens, en général, acceptent l'hégémonie des gens du spectacle dans la même sphère.

Dans le troisième article, «Iran's Regional Musical Traditions in the Twentieth Century: A Historical Overview ", pp. 417-440, Âmeneh Youssefzâdeh montre comment, au cours $\mathrm{du} \mathrm{XX}^{\mathrm{e}} \mathrm{s}$., les musiques régionales étaient traitées aussi bien par les instances officielles, selon les politiques culturelles d'avant et d'après la Révolution Islamique, que par les chercheurs ( $c f$. l'histoire de la collecte de ces musiques) et comment elles étaient présentes dans les festivals de musique et dans les œuvres des musiciens urbains.

Wendy S. DeBano, en se focalisant sur le quatrième festival de musique pour femmes (Jašnvāre-ye mūsīqī-ye gol-e yās) en 2002, essaie de montrer dans le quatrième article, «Enveloping Music in «Gender, Nation, and Islam: Women's Music Festivals in PostRevolutionary Iran ", pp. 441-462, comment les problèmes cruciaux de l'identité nationale, de la hiérarchie socio-culturelle, de la religiosité et de la féminité se rencontrent et sont soulignées dans ce genre de festival de la musique en Iran postrévolutionnaire.

7 Finalement, dans le dernier article, « Underground, Overground: Rock Music and Youth Discourses in Iran ", pp. 463-494, Laudan Nooshin étudie un cas très particulier de la vie musicale en Iran : la pratique de la musique rock, dont la présentation publique n'est pas autorisée, par certains jeunes musiciens urbains. Cette pratique crée, selon l'A., un espace alternatif qui s'oppose à l'espace officiel et où les jeunes peuvent s'exprimer, autrement que dans les discours officiels, sur les relations entre individu et société, modernité et tradition, local et global, profane et sacré.

\section{INDEX}

Thèmes : 17.1.Musique

\section{AUTEURS}

\section{RÉDACTION}

Directeur de la revue et secrétariats (Paris et Téhéran) 